Christopher Otrok ${ }^{1,2}$ / Panayiotis M. Pourpourides ${ }^{3}$

\title{
On the cyclicality of real wages and wage differentials
}

\author{
${ }^{1}$ Department of Economics, University of Missouri, Columbia, MO 65211, USA \\ 2 Federal Reserve Bank of St Louis, St. Louis, MO, USA \\ ${ }^{3}$ Cardiff Business School, Cardiff University, Aberconway Building, Colum Drive, Cardiff CF10 3EU, UK, E-mail: \\ pourpouridesp@cardiff.ac.uk
}

\begin{abstract}
:
Previous empirical literature suggests that estimated wage cyclicality depends on the structure of the relationship between real wages and an observed indicator of the business cycle that econometric models impose prior to estimation. This paper, alleviates the problem of imposing such structure by searching directly for the largest common cycles in longitudinal microdata using a Bayesian dynamic latent factor model. We find that the comovement of real wages is related to a common factor that exhibits a significant but imperfect correlation with the national unemployment rate. Among others, our findings indicate that the common factor explains, on average, no more than $9 \%$ of wage variation, it accounts for $20 \%$ or less of the wage variability for $88 \%$ of the workers in the sample and roughly half of the wages move procyclically while half move countercyclically. These facts are inconsistent with claims of a strong systematic relationship between real wages and business cycles.
\end{abstract}

Keywords: Bayesian analysis, business cycles, wage differentials, wages

JEL classification: C11, C13, C22, C23, C81, C82, J31

DOI: 10.1515/bejm-2017-0047

\section{Introduction}

The cyclicality of real wages is a crucial element that allows us to differentiate between competing theories of the labor market. Previous econometric studies impose structure on the relationship between real wages and an observed indicator of the business cycle (the unemployment rate) prior to estimation. In fact, the findings from the literature suggest that the estimated wage cyclicality depends on this structure: real wages are estimated to be mildly to strongly procyclical when wages are assumed to depend only on the current unemployment rate [e.g., Bils (1985), Keane, Moffitt, and Runkle (1988), Shin (1994), Solon, Barsky, and Parker (1994), and Shin and Solon (2006) and, more recently, Verdugo (2016)] whereas they are estimated to be acyclical when the real wage of each individual, in addition to the current unemployment rate (common across all wages), is assumed to also depend on 'appropriate' lagged values of the unemployment rate [e.g., Beaudry and DiNardo (1991)]. ${ }^{1}$ In this paper, we estimate wage comovement, which then allows us to draw conclusions about real wage cyclicality, avoiding the problem of imposing any a priori structure on the relationship between real wages and observed indicators of the business cycle. In particular, we provide new evidence using longitudinal microdata in conjunction with a relatively recent econometric approach, that of a dynamic factor model. ${ }^{2}$ The dynamic factor model searches directly for the largest common cycle in wage data, alleviating the problem of defining the cycle as any particular macroeconomic variable. The use of individual micro data allows us to determine whether the cyclicality of wages is specific to a certain subset of individuals, which alleviates the problem of composition bias. ${ }^{3}$ Our main objective is to investigate whether real wages comove substantially over the business cycle, and to disentangle the cyclical properties of wages for skilled (college) and unskilled (no college) workers. To do so, we employ a dynamic latent factor model in which real wages respond to common as well as skill-specific factors.

Our dynamic factor model is motivated by the fact that if real wages exhibit a systematic relationship with the business cycle, then there should be a common factor accounting for a considerable amount of their variability. Furthermore, from a macroeconomic perspective, wage cyclicality would imply that the common factor drives the majority of real wages in the same direction. We provide evidence that real wages do not comove substantially and do not exhibit strong comovement related to the aggregate business cycle. The common factor 
present in wage data that we estimate does in fact turn out to be correlated with the national unemployment rate. However, we show that no more than $9 \%$ of wage variability is attributed to the common factor. We also show that real wages do not exhibit a distinct pattern as regards to their response to the common factor. Finally, we confirm findings of previous studies in which the wages of skilled and unskilled workers exhibit roughly the same degree of cyclical variation.

The cyclical behavior of real wages enables us to draw inferences about different theories of the labor market as described analytically in Appendix A. In macro models, business cycles are driven by aggregate shocks and endogenous variables can be expressed as functions of the state of the world so that their solution is expressed in the form of an approximate dynamic factor model. A set of competing theories (models) impose a structure on the relationship between real wages and the business cycle which depends on the evolution of state variables. For instance, in Walrasian models real wages coincide with marginal productivity. Since marginal productivity (usually driven by an aggregate shock) is highly correlated with the business cycle, real wages appear to be strongly procyclical. On the other hand, a labor contracting model implies that real wages depend not only on marginal productivity, but also on an insurance component that results from bargaining between worker and firm. These two components offset each other in such a way that real wages become acyclical. ${ }^{4}$ Moreover, in models of this class, equilibrium real wages also depend on market conditions the time labor contracts are signed. In this case, real wages depend not only on the current state of the economy but also on previous states of the economy. In the appendix of the paper, we briefly describe the relevant feature of neoclassical and labor contracting models which determines how wages behave and demonstrate that the models have different implications for both the relationship between individual wages and the common factor, as well as the quantitative importance of the factor itself. The dynamic factor analysis in this paper can then be a direct test of the neoclassical model or, more generally, any model which imposes structure on the relationship between real wages and the business cycle. ${ }^{5}$ It has two advantages over a direct estimation of structural models. First, we can consider a large panel of workers of different types to see if the neoclassical implications hold for 'most' indviduals, or for at least a subset of workers. Second, our test of the model will not lead to a rejection simply because some other feature of the structural model (such as the consumption Euler equation) rejects the RBC model.

Our findings suggest that real wages behave in a manner more consistent with models of labor contracting, though other models may be as well. This is in the line of the findings presented by Cooley and Ogaki (1996) who show that the time series properties of real wages are compatible with Walrasian models only in the long-run, whereas in the short-run they are better explained by an optimal labor contract model. ${ }^{6}$ Finally, our evidence confirms the findings of Keane and Prasad (1993) in that the behavior of real wages of skilled and unskilled workers do not exhibit substantial differences over the business cycle. We reach this conclusion from the fact that the skill-specific factors we estimate are not quantitatively important.

Our results are distinct from the existing literature in the use of the individual level data coupled with the dynamic factor model. At the same time our work is part of a long history of studying the cyclical behavior of wages and it is useful to briefly review the main contributions. Given that the literature is too large and varied, our review will not be exhaustive. Several studies estimate econometric models using disaggregated data to control for composition and aggregation effects. In most of those studies, real wages are regressed on the current unemployment rate, as an indicator of the business cycle, and other worker-specific characteristics. Among others, these studies, include the work of Bils (1985), Keane, Moffitt, and Runkle (1988), Solon, Barsky, and Parker (1994), Shin (1994), Ziliak, Wilson, and Stone (1999), Shin and Solon (2006), and Verdugo (2016). Bils, Solon et al., Shin, Ziliak et al., Shin and Solon, and Verdugo, find that real wage acyclicality is simply a statistical illusion and that real wages are strongly procyclical. Using US data, Solon et al. find that the composition bias issue is quantitatively important. A similar result is reported by Verdugo who finds that real wages in the Eurozone are highly procyclical, while composition effects have been particularly large since 2008. Bils however, demonstrates that the impact of composition bias is not notably large and argues that wage procyclicality is due to the inclusion of overtime earnings. ${ }^{7}$ Keane et al report that real wages are only mildly procyclical after controling for sample selection bias. ${ }^{8}$ Beaudry and DiNardo (1991) on the other hand, demonstrate that when appropriate lagged values of the cyclical indicator are included in the regression then the estimated procyclicality of real wages dissapears.

Previous studies have found that the real wages of skilled workers exhibit different low frequency variation than that of the real wages of unskilled workers. Katz and Murphy (1992), find that this behavior can be explained by different demand shifts for skilled and unskilled labor. Motivated by those findings, Acemoglu (1998), develops a theoretical framework to show that the wage gap between skilled and unskilled workers as well as the changes in the demand for skills are due to skilled-biased technological change which is determined endogenously. Krusell et al. (2000), report empirical evidence showing that wage differentials are due to the existence of capital-skill complementarity which is present in the production process. These theoretical and empirical arguments have direct implications in building alternative theories of the labor market. These 
theories must also be consistent with the cyclical behavior of wage differentials and thus, knowledge of cyclical facts of skilled versus unskilled wages is essential. Within the context of our framework, if the cyclical properties of real wages for skilled and unskilled workers are not alike, then there should exist different skill-specific factors explaining a considerable portion of wage variability. We find that there is little evidence of significantly distinct cycles for these two groups of workers.

The remainder of the paper is organized as follows. Section 2 presents a description of our dataset which is extracted from the National Longitudinal Surveys (NLS). Section 3, introduces the model and Section 4 lays out our econometric framework and methodology. Section 5 presents our results and Section 6 concludes.

\section{The data}

Our data on hourly wages are taken from the National Longitudinal Survey (NLSY79 Cohort), which is a nationally representative sample of 12,686 men and women born in the years 1957 through 1964 . All respondents were interviewed annually from 1979 to 1994 . We use the time series from 1979 to 1993 and collect information from the survey on employment, wages and sociodemographic characteristics. ${ }^{9}$

The advantage of the NLS panel data set is that it avoids problems related to having a changing work force and enables us to control for various worker characteristics. Unlike the Michigan's Panel Study of Income Dynamics (PSID), where the hourly wage in a given year is the ratio of the annual income to the annual hours of work, in the NLS the respondents directly report their hourly rate of pay in the week of the interview. Thus, the advantage of using NLS over PSID is that hourly wages are less contaminated by recall bias. ${ }^{10,11}$ We accept only those respondents that meet the following restrictions: 1 ) Must be at least 18 years old at the interview date; 2) Are not self-employed;3) There must be at least 7 years of available time series observations; 4 ) Are not enrolled in school the last 2 years of the sample period.

After removing the respondents who do not meet our criteria our sample contains 2,123 individuals and 31,845 person-year observations. We provide further analysis of our sample by classifying individuals into 8 broadly defined categories on the basis of skills, gender and race. We define skilled workers as those having at least a college degree and unskilled workers as the remainder of the sample. Race is defined based on the information provided by NLS, which classifies the respondents into three race groups, Hispanic, Black and non-Black/non-Hispanic. We group the sample into two main categories. One category consists of Blacks and Hispanic and the other one consists of the remainder of the sample, which is assumed to be largely nonminority. A detailed description of the composition of our sample can be found in Table 1. The wage measure is deflated by the Consumer Price Index (CPI) to provide a real wage measure normalized in terms of 1983 CPI dollars. The data are log-first-differenced and demeaned before estimation. ${ }^{12}$

Table 1: Composition of the sample.

\begin{tabular}{|c|c|c|c|}
\hline Category & \# of people & $\%$ in sample & $\%$ of missing obs. \\
\hline skilled males minority & 40 & 1.90 & 0.86 \\
\hline skilled males nonminority & 89 & 4.19 & 1.80 \\
\hline skilled females minority & 60 & 2.82 & 1.16 \\
\hline skilled females nonminority & 98 & 4.61 & 1.99 \\
\hline unskilled males minority & 528 & 24.90 & 6.30 \\
\hline unskilled males nonminority & 452 & 21.30 & 4.88 \\
\hline unskilled females minority & 428 & 20.14 & 5.70 \\
\hline unskilled females nonminority & 428 & 20.14 & 5.08 \\
\hline aggregate & 2123 & 100.0 & 27.77 \\
\hline males & 1109 & 52.23 & 13.84 \\
\hline females & 1014 & 47.77 & 13.93 \\
\hline skilled & 287 & 13.52 & 5.81 \\
\hline unskilled & 1836 & 86.48 & 21.96 \\
\hline minority & 1056 & 49.74 & 14.02 \\
\hline nonminority & 1067 & 50.26 & 13.75 \\
\hline
\end{tabular}

One potential issue that we face is that our dataset is an unbalanced panel as missing observations constitute $27.7 \%$ of the sample. Missing observations arise in the NLS because either the respondent is not interviewed or he/she is enrolled at school or he/she is unemployed. Wage observations where respondents are enrolled at school but at the same time report a positive wage rate are treated as missing observations. (Information about missing observations for each category can be found in Table 1.) One approach to solving this problem 
is to simply drop the time series containing missing observations. Since this signifcantly reduces the sample size, and may induce a selection bias, we take an alternative approach. We treat the missing oberservations as random variables and estimate them as part of our econometric model. Our methodology for estimating the missing observations is described in Section 4 and Appendix B.

\section{The dynamic factor model}

To estimate the cyclical properties of real wages we use a dynamic factor model in the spirit of Sargent and Sims (1977) as implemented by Kose, Otrok, and Whiteman (2003). This statistical model differs from the models traditionally employed to estimate wage cyclicality. In previous work, wages are associated with cyclical indicators (eg. the unemployment rate). Of course, if one chooses the 'wrong' cyclical indicator the results will be biased towards finding acyclical wages. The factor model, by definition, extracts the largest common cycle(s) in the wage data. Hence, we are finding the maximum possible amount of cyclicality in the wage data. Our model then gives the best possible chance to the theories in favor of cyclical wages.

To be concrete, let $\mathbf{y}_{t}$ be a vector of real wages for $N$ individuals at time $t$. Then, $\mathbf{y}_{t}$ can be explained by a vector $\mathbf{f}_{t}$ of $K$ common factors and a vector $\varepsilon_{t}$ of $N$ individual-specific noise terms. We assume that $\mathbf{f}_{t}$ and $\varepsilon_{t}$ evolve according to the following autoregressions:

$$
\mathbf{f}_{t}={ }^{f}(L) \mathbf{f}_{t-1}+\mathbf{u}_{t}^{f}
$$

and

$$
\varepsilon_{t}=(L) \varepsilon_{t-1}+\mathbf{u}_{t}
$$

where $\phi^{f}(L)$ and $\phi(L)$ are diagonal $K \times Q$ and $N \times P$ matrices of polynomials in the lag operator, respectively. The vectors of disturbances $\mathbf{u}_{t}^{f}$ and $\mathbf{u}_{t}$ are assumed to be zero mean and normally distributed with

$$
E\left(\mathbf{u}_{t}^{f} \mathbf{u}_{\tau}^{f^{\prime}}\right)=\left\{\begin{array}{ll}
\mathbf{M}^{f} & \text { for } t=\tau \\
\mathbf{0} & \text { otherwise }
\end{array} \quad \text { and } E\left(\mathbf{u}_{t} \mathbf{u}_{\tau}^{\prime}\right)= \begin{cases}\mathbf{M} & \text { for } t=\tau \\
\mathbf{0} & \text { otherwise }\end{cases}\right.
$$

where $\mathbf{M}^{f}$ and $\mathbf{M}$ are diagonal matrices and $E\left(\mathbf{u}_{t}^{f} \mathbf{u}_{t}\right)=\mathbf{0}$. In other words, the factors are independent from each other and the individual-specific noise terms are independent across individuals. The statistical model for $\mathbf{y}_{t}$ is

$$
\mathbf{y}_{t}=\mathbf{b f}_{t}+\boldsymbol{\varepsilon}_{t}
$$

where $\mathbf{b}$ is a $N \times K$ matrix of factor loadings.

We focus our attention in characterizing the dynamic effects of three factors. The common dynamics of real wages across all individuals are captured by the common factor $f^{c}$. The factors $f^{s}$ (where $s=\operatorname{skilled}$ or unskilled) drive the wages of a subset of individuals with the same skill level. Thus, having panel data on $N$ individuals, each observed for $T$ time periods, our model for the real wage of individual $i$ is

$$
\begin{array}{r}
\qquad y_{i, t}=b_{c, i} f_{t}^{c}+b_{s, i} f_{t}^{\mathcal{S}}+\varepsilon_{i, t} \\
\text { for } i=1,2, . ., N ; s=\text { skilled or unskilled; } t=1, . ., T
\end{array}
$$

where $b_{j, i}$ is the 'factor loading' that captures the sensitivity of the wage of worker $i$ to factor $j$. Note that for a skilled worker the factor loading on the unskilled factor is constrained to zero, and vice versa for the unskilled worker. The corresponding idiosyncratic error $\varepsilon_{i, t}$ follows a $p_{i}$-order autoregression:

$$
\varepsilon_{i, t}=\phi_{i, 1} \varepsilon_{i, t-1}+\phi_{i, 2} \varepsilon_{i, t-2}+\cdots+\phi_{i, p_{i}} \varepsilon_{i, t-p_{i}}+u_{i, t}
$$

where $\phi_{i, j}$ represents the exposure of the idiosyncratic error to its $j$ th lag and $u_{i, t} \sim \operatorname{iid} N\left(0, \sigma_{i}^{2}\right)$. Likewise, the law of motion of factor $j$ is given by the $A R\left(q_{i}\right)$ process: 


$$
\begin{gathered}
f_{t}^{j}=\phi_{f k, 1} f_{t-1}^{j}+\phi_{f k, 2} f_{t-2}^{j}+\cdots+\phi_{f k, q_{i}} f_{t-q_{i}}^{j}+u_{k, t}^{f} \\
\text { for } k=c, s
\end{gathered}
$$

where $\phi_{f k, j}$ represents the exposure of factor $k$ to its $j$ th lag and $u_{k, t}^{f} \sim \operatorname{iidN}\left(0, \sigma_{f, k}^{2}\right)$.

\section{Estimation}

We estimate the factors and the parameters of the econometric model 3.4-3.6 using the Bayesian approach developed in Otrok and Whiteman (1998). We simulate from the joint posterior of the parameters and factors using a Markov Chain Monte Carlo alogorithm. The main part of their procedure is a Gibbs sampler that sequentially draws the parameters conditional on the factors, and then the factors conditional on the parameters. ${ }^{13}$

Since the innovations to idiosyncratic terms are uncorrelated, conditional on the factors, the system 4.4 consists of $N$ independent regression models. Hence, conditional on the factors, we use Chib and Greenberg (1994) procedure to draw the regression parameters separately for each equation. Since the model has 2,123 equations this feature of their procedure makes the estimation feasible for our dataset. A full derivation and description of the relevant conditional densities can be found in Otrok and Whiteman (1998) .

The (conjugate) prior densities for $\mathbf{b}_{i}, \boldsymbol{\phi}_{i}, \boldsymbol{\phi}_{f k}$ and $\sigma_{i}^{2}$ are chosen to be the same as those used in Otrok and Whiteman (1998). Specifically, the prior for the factor loadings $\mathbf{b}_{i}$ is Gausian with zero mean and precision (1/variance) equal to 0.01 . The persistence parameters of the innovation and factor processes $\phi_{i}$ and $\phi_{f k}$ are also Gaussian with zero mean and precision equal to 0.85 for all lags. The prior of the idiosyncratic innovation variance $\sigma_{i}^{2}$ is an inverted gamma $\sim(\alpha / 2, \beta / 2)$ with $\alpha=6$ and $\beta=0.001$. These priors are fairly diffuse and the main results are not very sensitive to values of prior parameters around the ones chosen.

Our dataset poses a technical problem due to missing observations for wages in some years for many of the survey respondents. Instead of ommiting the time series we assume that the missing observations are random variables and we estimate these missing observations as part of our econometric model. We do so by first deriving the distribution of the missing data points conditional on the parameters and factors. This distribution depends on both cross-sectional information as well as the time series data before and after the missing observation. Intuitively, the distribution depends on both a 'forecast' and 'backcast' of the missing observation using the univariate time series data itself, and the parameters governing the dynamics of the time series. It also includes cross-sectional information: the factor loading is used along with the factor itself to 'predict' the missing value. Our procedure combines both types of information. A direct way to do this is by applying the Kalman filter and then smoothing the means and the variances by backward induction. Details of the procedure are in Appendix B. ${ }^{14}$

Our Gibbs sampler then has three blocks. In block one we condition on factors and model parameters to draw the missing observations (for those time series with missing data). Then, in block two we treat the missing data drawn in block one as data and draw the model parameters. Finally, conditional on the drawn missing data and parameters we draw the factors. The procedure is repeated 5000 times after an initial burnin of 500 draws.

\section{Empirical results}

Our primary interest is to provide answers to two questions: First, do real wages exhibit a systematic relationship with the business cycle? Second, are the wages of skilled and unskilled workers subject to a significantly different degree of cyclical variation? To answer the first question we focus on the importance of the common factor in equation 4 . To answer the second question we focus on the relative contribution of the skill factors in equation 4 in accounting for real wage fluctuations. Since the factors (common and skill specific) are estimated simultaneously, the skill factors are capturing how much comovement there is for a specific skill group conditional on comovement already accounted for by the factor common to all wages. That is, skilled (or unskilled) wages may comove simply because all wages comove. Our model determines instead how much comovement there is in skilled wages that is not common to wages of all skill levels. This conditioning is important, as it alleviates the danger of looking only at, say, the wages of skilled workers, and mistakenly concluding that skilled wages have a common cycle, when that cycle is in fact common to a wider array of individuals. 


\subsection{The dynamic factors}

Figure 1 presents the mean of the posterior distribution of the factors along with corresponding 95 percent posterior coverage intervals. The bounds of the confidence intervals are tight which shows that the factors are estimated quite precisely. The common factor is characterized by the troughs of 1983 and 1990 and the peak of 1987. The troughs occur at roughly the same time that NBER recessions occur. In particular, the trough of the 1983 lags the NBER recession of the 1982 whereas the trough of 1990 leads the NBER recession of $1991 .^{15}$

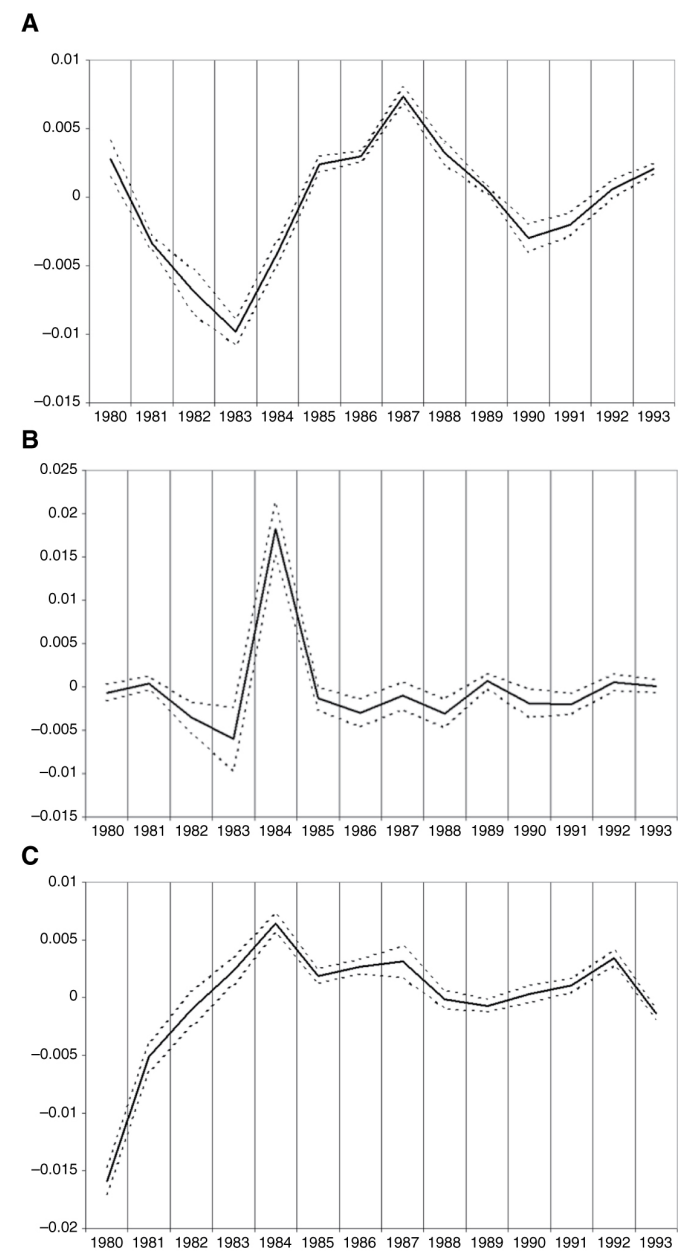

Figure 1: Dynamic factors (means, upper and lower bounds), 1980-1993. (A) Common factor; (B) Skilled factor; (C) Unskilled factor.

The variable used by the previous studies as an indicator of the business cycle is the national unemployment rate. In fact, our common (wage) factor exhibits a strong negative correlation $(-0.69)$ with the national unemployment rate (in levels) which indicates that the unemployment indicator captures a good portion of real wage cyclicality. However, the correlation is not perfect so assuming that unemployment is the common wage cycle underestimates the degree of wage cyclicality to a modest extent. It is the case that our estimates suggest that macroeconomic conditions are relevant, at least to some extent, for the cyclical behavior of real wages.

We interpret the factor as being related to the macroeconomic business cycle. In Figure 2 we plot the wage factor along with TFP, and also the wage factor with a macro factor, The macro factor is estimated using unemployment, TFP, real GDP growth, growth of the price of real investment, and the growth of labor productivity. As is evident from the figure, there is a correspondence of the wage factor with the macro factor. At the same time, the wage factor does not move very closely with TFP. The wage factor then is related to a broad cross section of macroeconomic variables. While TFP does have a relationship with the wage factor, it is clearly not very strong. This is precisely why we do not want to study the cyclicality of wages using either TFP or a single macroeconomic variable. ${ }^{16}$ 


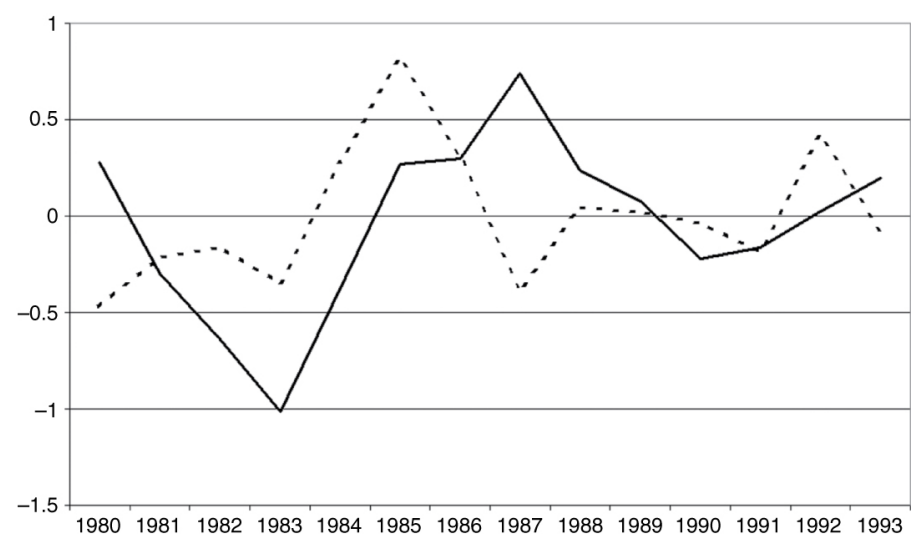

B

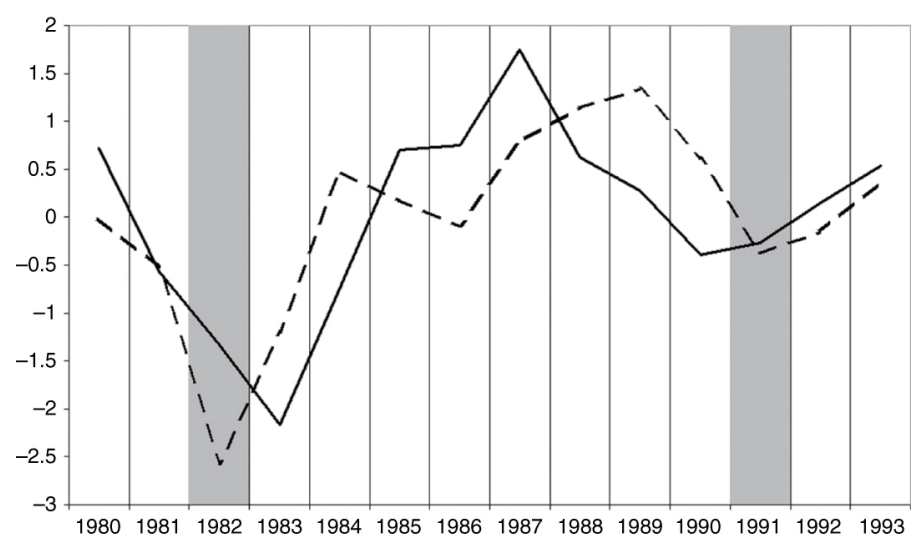

Figure 2: The Wage (common) factor vs. other factors, 1980-1993. (A) TFP (- -) vs. Wage Factor (-); (B) Macro factor (- -) vs. Wage factor $(-)$.

The skill-specific factors appear less cyclical than the aggregate factor and have distinct dynamics from each other. The correlation coefficient between the skilled and the unskilled factors is 0.26 which signifies that real wages embody a distinct component which is specific to skills. ${ }^{17}$ The correlation coefficient between the skill factors and the unemployment rate is almost zero. Both factors exhibit substantial variation until 1985 and relatively smooth fluctuations afterwards. ${ }^{18}$

To examine whether common fluctuations are more persistent than skill specific fluctuations we report the first-order autocorrelation coefficients of the factors. Our estimates indicate that aggregate common fluctuations are highly persistent just like the unemployment rate. The common fluctuations of unskilled wages are also highly persistent with an autocorrelation coefficient of 0.68 . Contrary to the common and the unskilled factors, the skilled factor exhibits a negative autocorrelation of -0.21 which suggests that it is weakly mean reverting. The differing dynamics of the skilled factor suggests that there are forces unique to skilled workers driving their wages. If we interpret this in light of the theoretical models presented in the appendix, then this would suggest skill-specific productivity shocks. We do not push this interpretation very hard though, since we will see that these factors are not quantitatively important. Next we examine the direction to which a change in each of the factors affects real wages. Figure 3 displays the cumulative distribution functions (CDFs) of the factor loadings. The CDFs illustrate that roughly half of real wages in our sample respond positively to the factors while the other half respond negatively. Thus, there is no distinct pattern of the responses of real wages to the common factors. 
A

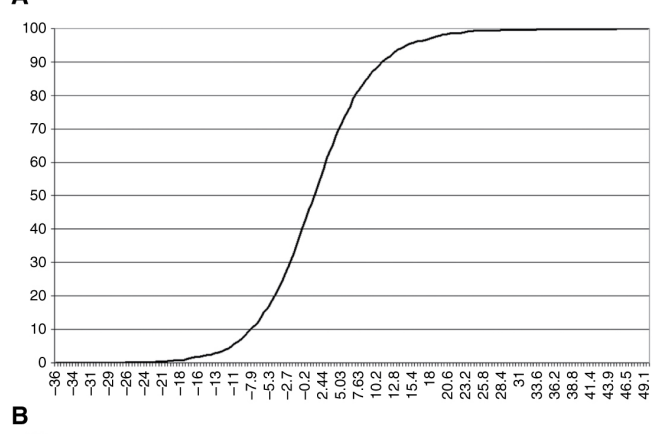

B
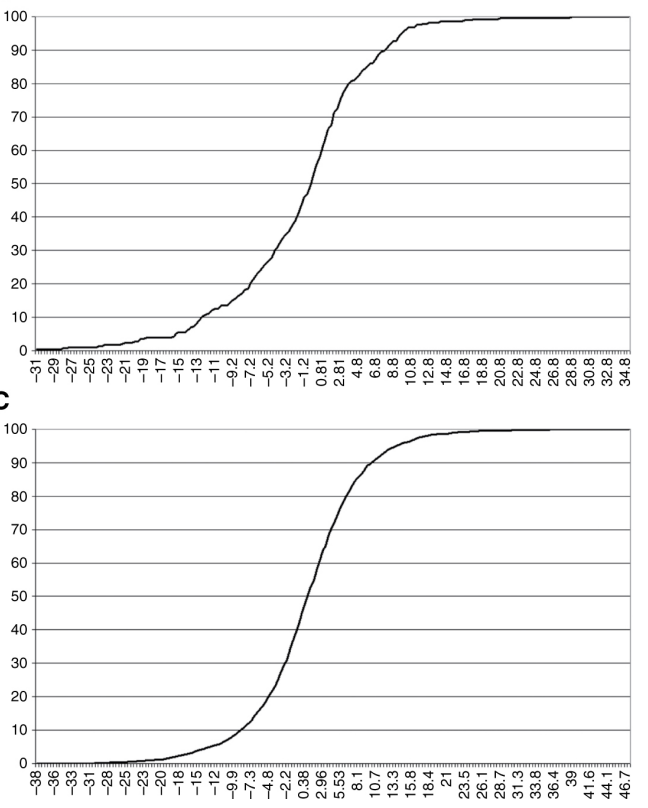

Figure 3: Factor loading cummulative distributions. (A) Common factor loading distribution; (B) Skilled factor loading distribution; (C) Unskilled factor loading distribution.

Macroeconomic models of the labor market can be classified based on the mechanism according to which real wages are being determined and the implied cyclicality of the latter. Surveying all relevant models is not the objective of this paper. However, in the appendix we show that the factor model can be employed as a test of one model of the labor market - the Walrasian spot market model of wages. Testing via the factor model enable us to consider a large panel of longitudinal micro data on real wages to check whether the neoclassical implications hold for "most" individuals or a subset of them. The factor model also eliminates the possibility of rejecting the theory simply because some irrelevant feature of the theoretical model is problematic. As shown in the appendix, a neoclassical model of the labor market where marginal productivities depend on aggregate shocks (commonly, an aggregate technology shock) would imply that all wages respond with the same sign to the common factor. For instance, an improvement in technology would increase the wages of all workers. Therefore, in such model, we expect that real wages would exhibit a positive and strong correlation with the business cycle. Our results are strongly at odds with the spot market/Walrasian assumption at the heart of RBC models.

On the other hand, a wage contracting model with some heterogeneity in preferences (e.g., in risk aversion) may exhibit responses with different signs for a single change in market conditions (which may reflect improvement or deterioration of the level of technology). The latter is consistent with factor loading coefficients that differ in sign and magnitude. Our results indicate that the common factor exhibits responses with different signs which suggests that the data are inconsistent with the predictions of a Walrasian model but consistent with predictions of a labor contracting model. There may of course be many models consistent with these results, our main point is that the RBC model is not, and we can identify at least one reasonable alternative.

\subsection{Variance decompositions}

To examine the quantitative significance of the cyclical factors we estimate the contribution of each of them to the overall variability of observables. Since the factors and the idiosyncratic component are orthogonal to each 
other it is straightforward to partition the variance of each observable into the fraction that is due to each of the underlying factors and the idiosyncratic component by applying the Var operator to equation 3.4. Reporting the full posterior distributions of all 2,123 posteriors is infeasible, so instead we report information on the distribution of the posterior means of the 2,123 variance decompositions. In most cases that we examined the posterior coverage intervals were tighly distributed about the mean. Figure 4 displays frequencies of variance decompositions across the skilled, the unskilled and the whole sample while Figure 5 displays CDFs of the corresponding variance decompositions. Table 2 presents analytically the number of individuals falling in each interval of variance shares attributable to each of the factors and the idiosyncratic component.

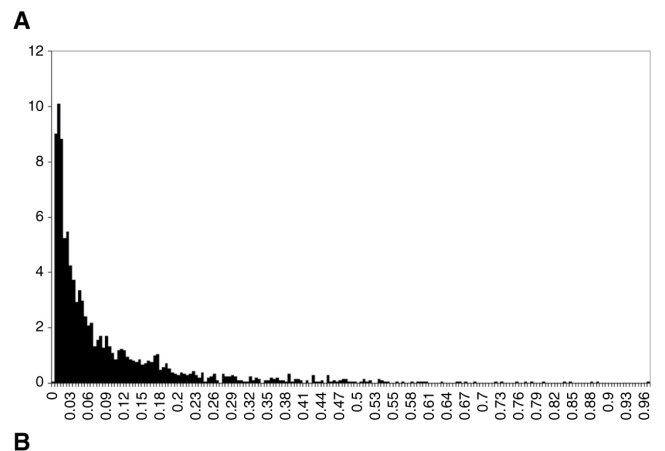

B

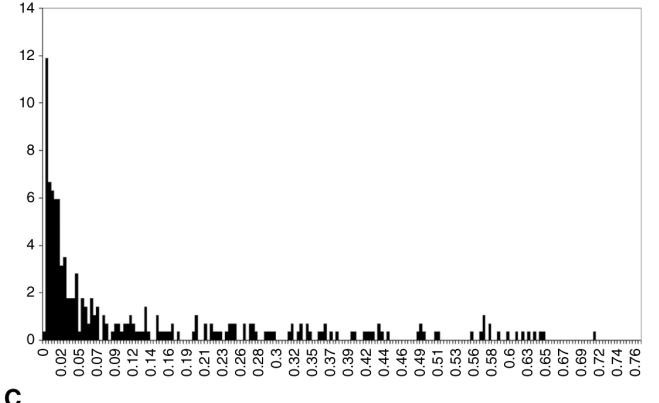

C

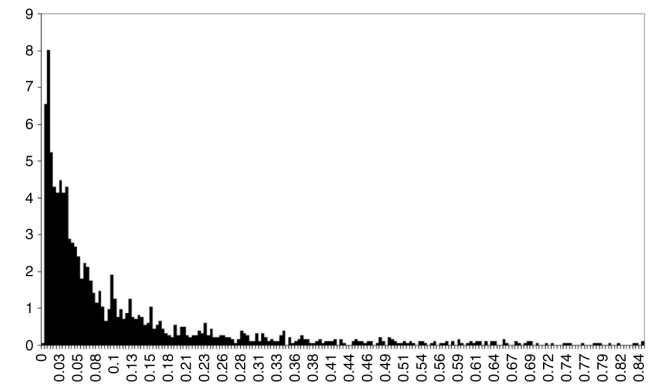

Figure 4: Histograms (frequencies) of variance decompositions. (A) Common factor; (B) Skilled factor; (C) Unskilled factor. 
A
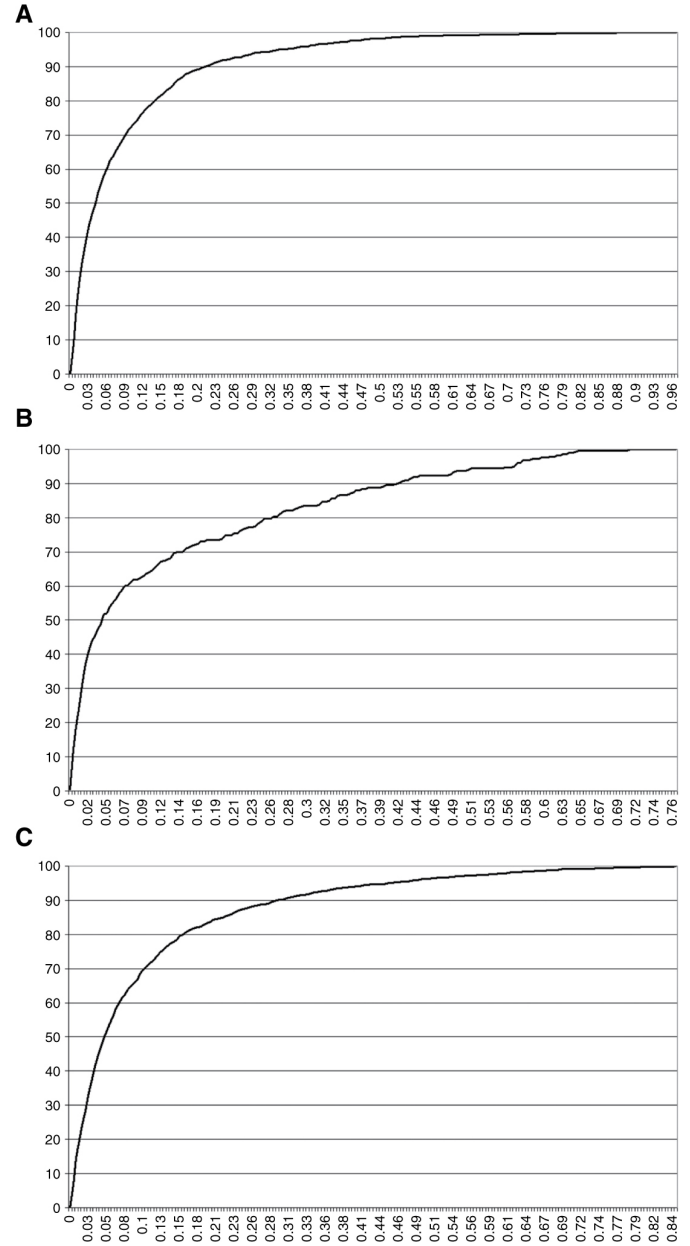

Figure 5: Cumulative distribution functions of the variance decompositions. (A) Common factor; (B) Skilled factor; (C) Unskilled factor. 


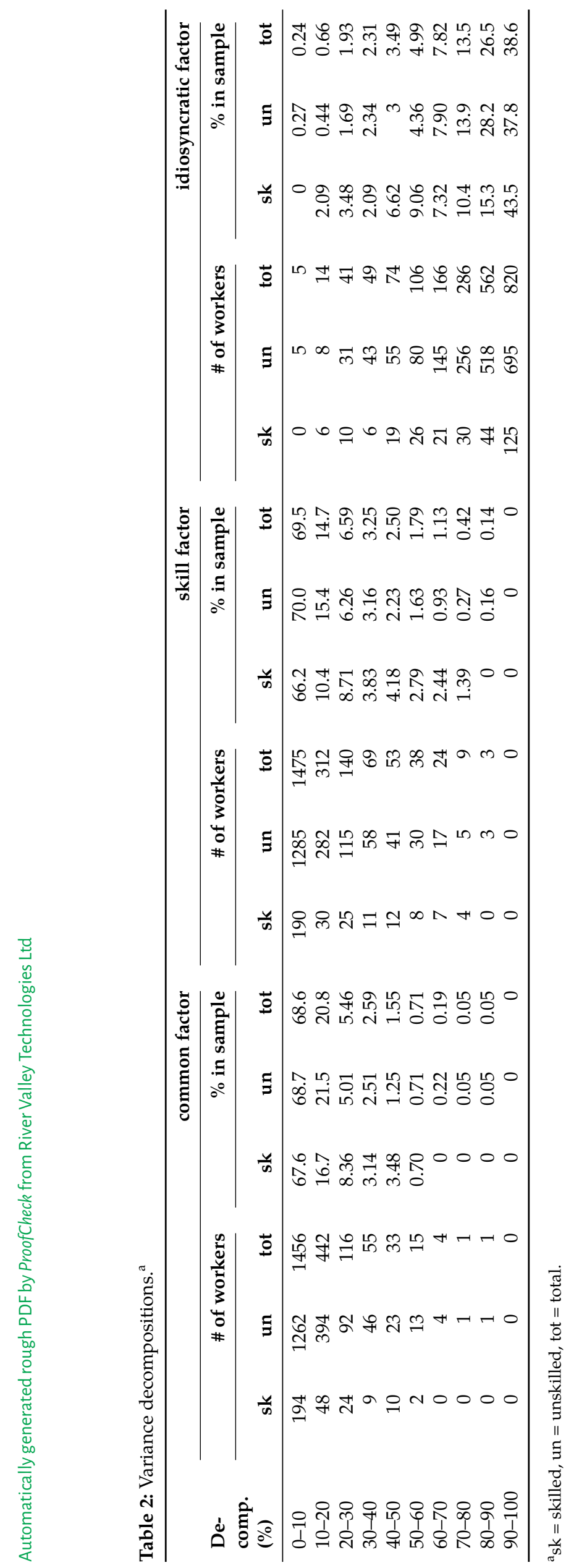


The common factor explains, on average, no more than $9 \%$ of the variance of real wages. We obtain similar results when we examine the impact of the factor separately on skilled and unskilled wages. Overall, the common factor accounts for $20 \%$ or less of the wage variability for $88 \%$ of the workers in the sample. The share of variance attributable to the common factor exceeds $50 \%$ for only $1 \%$ of the workers. In other words, the wages of only $1 \%$ of the respondents are overwhelmingly influenced by current economic conditions, as reflected through the common factor. These results show that the factor plays a relatively minor role in accounting for wage movements over the business cycle. Consequently, the explanatory power of the common factor is inadequate to justify claims for strong procyclical or countercyclical movements of real wages. Likewise, the skill factor explains, on average, no more than $10 \%$ of wage variability and accounts for $20 \%$ or less of wage variability for $84 \%$ of the workers in the sample. Those findings reinforce the evidence of previous studies which show that skilled and unskilled wages face essentially the same degree of cyclical variation.

These results are also inconsistent with a fixed nominal wage contract model. If we augment the neoclassical model in Appendix A.1. with a model where nominal wages are set for a fixed number of periods, then we would find that at least half, or a quarter of the wages, depending on the nominal wage contract length, would depend almost completely on the common factor. For example, if we have nominal wages fixed for 1 period, and half of workers get to change wages in a given period, then our common factor would find that more than half of the workers respond to the common factor. ${ }^{19}$

Notably, the idiosyncratic component is an important factor of wage fluctuations. It can explain more than $70 \%$ of wage variability for $78 \%$ of the workers. It is possible that this residual may include the effects of characteristics such as gender and race. To examine the robustness of our main results we extend our model by including gender and race factors. Specifically, we assume that there is a specific factor driving the wages of male workers and a separate factor driving the wages of female workers. As for the race characteristics we follow the NLS classification and assume two broadly defined race factors, one driving the wages of blacks and hispanics and another driving the wages of the remainder. We call the latter group nonminority and the former group minority. For instance, in this setting, the real wage of a skilled female worker who belongs to a minority group is driven by five factors, one that drives the wages of all workers, one that drives the wages of all skilled workers, one that drives the wages of all female workers, one that drives the wages of all minority workers and finally a factor that is specific to the worker. We find that the gender and the race factors have little to no explanatory power and do not change our main results. Thus, they are not retained in the final statistical model.

\section{Concluding remarks}

The cyclical behavior of real wages has long been a central issue in macroeconomics. Our contribution to this literature is to use a dynamic factor model with longitudinal data to find the largest possible common cycle in real wages. The advantage of this approach over previous approaches is that it does not impose structure on the relationship between real wages and observed indicators of the business cycle prior to estimation. Our approach also allows us to use longitudinal micro data from the NLS to control for composition and aggregation effects. Our model allows us to analyze the degree and the nature of the comovement of real wages across the entire population as well as separately for skilled and unskilled workers. It also enables us to quantify the contribution of each factor in wage variability.

We find that the common factor exhibits a significant but not perfect correlation with the national unemployment rate which is the common component of real wages assumed by previous studies. This indicates that macroeconomic conditions have indeed an impact on real wages. Nevertheless, variance decompositions show that, on average, the common factor accounts for only a small fraction of wage fluctuations. Furthermore, roughly half the wages are procyclical and half are countercyclical. These results are not consistent with neoclassical models of labor markets. Our findings also suggest that although skilled and unskilled wages are driven by different common skill factors, these factors cannot explain a significant portion of wage variability.

\section{Acknowledgement}

We thank Julie Yates (Bureau of Labor Statistics) and Steve McClaskie (National Longitudinal Surveys user services) for information and help with the data. 


\section{Appendix}

\section{A The factor model and two theoretical models}

\section{A.1 A neoclassical model}

The dynamic factor model of Section 4 can be motivated by a standard real business cycle model augmented with a model of measurement error induced by the agency gathering data. This motivation follows directly from the work of Sargent (1989). We start with a 'textbook' real business cycle model, that of King, Plosser, and Rebelo (1988), which specifies preferences, technology and budget constraints. Using standard parametric functional forms for preferences and technology the model can be log-linearized and solved. ${ }^{20}$ As is well known the solution of this model takes the form of a state law of motion and set of decision rules for observable variables:

$$
\begin{gathered}
\mathbf{S}_{t+1}=\boldsymbol{\Phi} \mathbf{S}_{t}+\mathbf{E}_{t+1} \\
\mathbf{Y}_{t}=\mathbf{H} \mathbf{S}_{t}
\end{gathered}
$$

The first system of equations describes the dynamic evolution of the vector of state variables and exogenous shocks, such as capital and technology. The second system of equations are the decision rules, linking the vector of endogenous choices, $\mathbf{Y}_{t}$, to the current state vector, $\mathbf{S}_{t}$. Typical decision variables are labor effort and consumption. Of course, the real wage would appear in $\mathbf{Y}_{t}$ as well.

As is well known, the real wage of the representative agent in this model is highly procyclical as the wage is equal to the marginal product of labor. To clarify this implication we follow the conventional way to decentralize the Pareto optimal equilibria of the model by assuming spot-competitive labor markets. Let the utility of agent $i, U^{i}$, be defined over consumption, $C_{i t}$, and work effort, $H_{i t}$ such that $U_{C}^{i}>0, U_{C C}^{i}<0, U_{H}^{i}<0$ and $U_{H H}^{i}<0$, where subscripts denote derivatives. Let $\theta_{t}$ be an exogenous state variable which is the driving force of business cycle fluctuations. Without loss of generality, since in RBC models, $\theta_{t}$ commonly denotes the level of neutral technology, we will simply call $\theta_{t}$ technology. ${ }^{21}$ Let $\psi_{i}\left(\theta_{t}\right)$ denote the agent's marginal productivity which is an increasing function of technology $\theta_{t}$. The intratemporal efficiency condition derived from an RBC model is

$$
\frac{-U_{H}^{i}\left(C_{i t}, H_{i t}\right)}{U_{C}^{i}\left(C_{i t}, H_{i t}\right)}=\psi_{i}\left(\theta_{t}\right)
$$

This condition results from the agent equating his marginal rate of substitution between consumption and leisure to the real wage, while firms choose labor such that the marginal product of labor equals the real wage. The spot-market equilibrium then implies that real wages equal marginal productivities. Consequently, under spot-competitive labor markets we expect that over the business cycle there is a common (macro) component, $\theta$, driving the real wages of all agents, and that these wages move in the same direction.

Our extension of this model assumes that we do not get to observe the 'true' real wage. Instead, we have many noisy observations on individual wages from this competitive spot labor market. The noise is induced by a data-gathering agency which must survey individuals to find out their wages. These survey data are riddled with errors, both recall errors from the agents and statistical errors from the agency itself. Our second system of equations then becomes:

$$
\mathbf{Y}_{t}=\mathbf{H S}_{t}+\mathbf{U}_{t}
$$

where $\mathbf{U}_{U}$ represents the measurement error and the $\mathbf{Y}_{t}$ vector contains the full set of indivudals surveyed.

The empirical model we will use in this paper, a dynamic factor model, is motivated directly from equations 7 and 10. These equations take the same general form as a dynamic factor model. To make this link concrete consider the dynamic factor representation for a vector of wage data $\mathbf{y}_{t}$ :

$$
\mathbf{y}_{t}=\mathbf{b f}_{t}+\boldsymbol{\varepsilon}_{t}
$$


where $\mathbf{b}$ is a $N \times K$ matrix of factor loadings. The factor $\mathbf{f}_{t}$ is assumed to follow an autoregressive process:

$$
\mathbf{f}_{t}=\phi^{f}(L) \mathbf{f}_{t-1}+\mathbf{u}_{t}^{f}
$$

It is clear from comparing equations 7 and 10 with equations 11 and 12 that the dynamic factor model takes the same form as the linearized solution to the real business cycle model with measurement error. Were one to simulate data from the RBC model and estimate a factor model on the simulated data, the estimated dynamic factor would then be the common state variable (e.g., technology shock) in the business cycle model. When we turn to actual data, if the neoclassical labor market embodying this model is largely correct, then when we estimate the factor model on wage data we should have two key results. First, as long as the wage data are not dominated by measurement errors, the common factor should be quantitatively important for explaining real wage dynamics. Second, the wages should all respond with the same sign to this common factor since in the business cycle model all wages respond positively to changes in productivity.

\section{A.2 A wage contracting model}

Our second labor market model is based on an alternative way to decentralize the Pareto optimal equilibria by considering a model where agents trade labor contracts. In such a model, wages and employment are specified in a contract which is the outcome of dynamic bargaining between workers and firms. The contract, $\left\{w^{i}\left(\theta_{t}\right)\right.$, $H^{i}\left(\theta_{t}\right)$ \}, consists of an hourly wage rate and hours of work that are contingent on the future state of technology. The contract is such that the efficiency condition 9 holds, but the hourly wage rate is not necessarily equal to $\psi_{i}\left(\theta_{t}\right)$. The hourly wage not only responds to changes in productivity but also provides insurance to risk averse agents against business cycle fluctuations. ${ }^{22}$ Contrary to the spot market case, under reasonable assumptions, in equilibrium the wage will not be strongly correlated with productivity. This is due to the fact that the wage embodies an insurance component which minimizes their fluctuations. Furthermore, a given change in $\theta$ may induce the wages of some agents to increase while others to decrease. Hence, responses of different signs to a given change in the common component are consistent with the theory of implicit contracts. To illustrate these two points, we provide a simple example where consumption equals labor earnings that is, $C_{i t}=w_{t}^{i} H_{i t}$, and the agents differ in terms of their aversion toward risk. Assuming separable CRRA preferences, condition 9 can be solved for the equilibrium wage (see Boldrin and Horvath (1995)): ${ }^{23}$

$$
w_{t}^{i}=\delta_{i}\left[\psi_{i}\left(\theta_{t}\right)\right]^{\frac{1}{\lambda_{i}}}\left[\frac{1-H_{i t}}{H_{i t}}\right]
$$

where $\delta_{i}>0$ and $\lambda_{i}$ is the agent's coefficient of risk aversion. (Note that the linearized version of equation 13 would enter the decision rules 8 or 10 in the state space system describing the model dynamics.) In this case, the equilibrium wage is comprised of two components, productivity and insurance (which is the ratio of leisure to labor). Productivity is strongly procyclical whereas the insurance component is countercyclical because hours of work are procyclical. The latter offsets the increases (decreases) in productivity and thus, wages do not appear to respond strongly to technology shocks. Notice that parameter $\lambda_{i}$ controls the elasticity of the hourly wage to the marginal product of labor fluctuations. Depending on the value of $\lambda_{i}$, for some individuals the effect of the insurance component may dominate the effect of productivity and thereby, the change in their wage, in response to an increase in $\theta$, will have a negative sign. The more risk averse an agent is the more likely she/he is to have a negative wage response to an increase in $\theta$. To summarize, the contracting model first implies that real wages will not exhibit a strong commmon cycle, implying that any common dynamic factor should have little explanatory power for real wage fluctuations. Second, if there is heterogeneity in preferences then the model predicts that the factor loading coefficients in the dynamic factor model will have both positive and negative signs. ${ }^{24}$

\section{B Factor models with unbalanced panels}

In this appendix we describe the procedure for estimating the missing observations. This procedure forms one block of our Gibbs sampler. In block one we draw the parameters conditional on factors and missing data. In block two we draw the factors conditional on parameters and missing data. In block three we draw the missing data conditional on parameters and factors. In essence, we fill in the missing observations of the unbalanced 
panel using information in both the model and available data. It is this last block that we describe in this appendix. The first two blocks are described in Otrok and Whiteman (1998) .

Let $\xi_{i, t}=\phi_{i, 1} \xi_{i, t-1}+\cdots+\phi_{i, p_{i}} \xi_{i, t-p_{i}}+u_{i, t}$ where $\xi_{i, t}=y_{i, t}-b_{c, i} f_{t}^{c}-b_{s, i} f_{t}^{s}$. Then, the following state space system is obtained:

$$
\begin{gathered}
\mathbf{y}_{i, t}=\mathbf{A}_{i}^{\prime} \mathbf{x}_{t}+\mathbf{H}^{\prime} \xi_{i, t}+\mathbf{w}_{i, t} \\
\xi_{i, t+1}=\mathbf{F}_{i} \xi_{i, t}+\mathbf{v}_{i, t+1}
\end{gathered}
$$

where

$$
\begin{aligned}
& \mathbf{y}_{i, t}=y_{i, t}, \xi_{i, t}=\left[\begin{array}{lll}
\xi_{i, t} \xi_{i, t-1} & \cdots \xi_{i, t-p_{i}+1}
\end{array}\right]^{\prime}, \mathbf{x}_{t}=\left[\begin{array}{lllll}
1 f_{t-1}^{c} & \cdots f_{t-q_{i}}^{c} & f_{t-1}^{s} & \cdots & f_{t-q_{i}}^{s k}
\end{array}\right]^{\prime} \\
& \mathbf{w}_{i, t}=b_{c, i} u_{c, t}^{f}+b_{s, i} u_{s, t}^{f}, \mathbf{v}_{i, t}=\left[u_{i, t} \mathbf{0}_{1 x\left(p_{i}-1\right)} \quad\right]^{\prime}, \mathbf{A}_{i}^{\prime}=\mathbf{B}_{i} \cdot \mathbf{\Phi}, \mathbf{B}_{i}=\left[b_{c, i} b_{s, i}\right] \\
& \mathbf{H}^{\prime}=\left[\begin{array}{l}
1 \mathbf{0}_{1 x\left(p_{i}-1\right)}
\end{array}\right], \boldsymbol{\Phi}=\left[\begin{array}{rrr}
\phi_{c, 1} \cdots & \phi_{c, q_{i}} 0 & \cdots 0 \\
0 \cdots & 0 \phi_{s, 1} & \cdots \phi_{s, q_{i}}
\end{array}\right], \mathbf{F}_{i}=\left[\begin{array}{rr}
\phi_{i, 1} \cdots & \phi_{i, p_{i}-1} \phi_{i, p_{i}} \\
\mathbf{I}_{\left(p_{i}-1\right) x\left(p_{i}-1\right)} & \mathbf{0}_{\left(p_{i}-1\right) x 1}
\end{array}\right]
\end{aligned}
$$

The variance matrix of $\mathbf{v}_{i, t}$ is

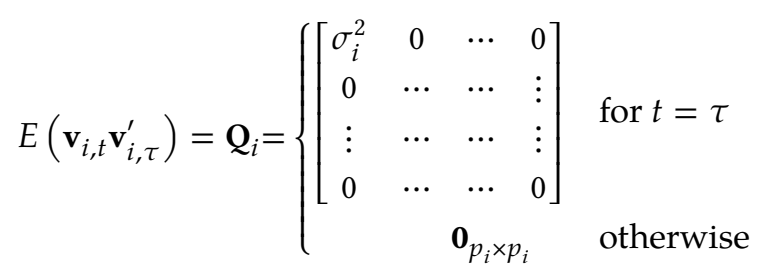

Consequently, the system $14-15$ satisfies the following conditions:

1. $E\left(\mathbf{w}_{i, t}^{2}\right)=b_{c, i}^{2} \sigma_{f, c}^{2}+b_{s, i}^{2} \sigma_{f, s}^{2}=\mathbf{R}_{i}$

2. $E\left(\mathbf{w}_{i, t} \mathbf{w}_{i, \tau}\right)=\mathbf{0}$, and $E\left(\mathbf{v}_{i, t} \mathbf{w}_{i, \tau}\right)=\mathbf{0}$ for all $t$ and $\tau$

Equations 14 and 15 are the observation and state equations, respectively. The recursion of the Kalman filter begins with $\widehat{\zeta}_{i, 0 \mid 0}$ which denotes the unconditional mean of $\boldsymbol{\xi}_{i, 1}$, where $\widehat{\boldsymbol{\xi}}_{i, 0 \mid 0}=E\left(\boldsymbol{\xi}_{i, 1}\right)=\mathbf{0}$, The asssociated Mean Square Error (MSE) is $\mathbf{P}_{i, 0 \mid 0}=\boldsymbol{\Sigma}=E\left(\boldsymbol{\xi}_{i, 1} \boldsymbol{\xi}_{i, 1}^{\prime}\right)$ where $\boldsymbol{\Sigma}=\boldsymbol{F} \boldsymbol{\Sigma} \boldsymbol{F}^{\prime}+\mathbf{Q}$. To enable the recursion steps we replace missing observations with values drawn from the distribution of the data, ${ }^{25}$

$$
L\left(y_{i, t} / \boldsymbol{\phi}, \xi_{i, t}, \ldots, \xi_{i, t-p}\right)=\left(2 \pi \sigma_{i}^{2}\right)^{-1 / 2} \exp \left\{-\frac{1}{2 \sigma_{i}^{2}}\left(y_{i, t}-\hat{y}_{i, t / t-1}\right)^{2}\right\}
$$

where $\hat{y}_{i, t / t-1}=y_{i, t}-\xi_{i, t}+\phi_{i, 1} \xi_{i, t-1}+\cdots+\phi_{i, p} \xi_{i, t-p}$. The transition from $\widehat{\xi}_{i, t-1 \mid t-1}$ and $\mathbf{P}_{i, t-1 \mid t-1}$ to $\widehat{\boldsymbol{\xi}}_{i, t \mid t}$ and $\mathbf{P}_{i, t \mid t}$ is given by the following set of equations ${ }^{26}$

$$
\begin{gathered}
\widehat{\boldsymbol{\xi}}_{i, t \mid t-1}=\mathbf{F}_{i} \widehat{\boldsymbol{\xi}}_{i, t-1 \mid t-1} \\
\mathbf{P}_{i, t \mid t-1}=\mathbf{F}_{i} \mathbf{P}_{i, t-1 \mid t-1} \mathbf{F}_{i}^{\prime}+\mathbf{Q}_{i} \\
\hat{\mathbf{y}}_{t \mid t-1}=\mathbf{A}_{i}^{\prime} \mathbf{x}_{t}+\mathbf{H}^{\prime} \widehat{\boldsymbol{\xi}}_{i, t \mid t-1}
\end{gathered}
$$




$$
\widehat{\boldsymbol{\zeta}}_{i, t \mid t}=\widehat{\boldsymbol{\xi}}_{i, t \mid t-1}+\mathbf{P}_{i, t \mid t-1} \mathbf{H}\left(\mathbf{H}^{\prime} \mathbf{P}_{i, t \mid t-1} \mathbf{H}+\mathbf{R}_{i}\right)^{-1}\left(\mathbf{y}_{t}-\hat{\mathbf{y}}_{t \mid t-1}\right)
$$

$$
\mathbf{P}_{i, t \mid t}=\mathbf{P}_{i, t \mid t-1}-\mathbf{P}_{i, t \mid t-1} \mathbf{H}\left(\mathbf{H}^{\prime} \mathbf{P}_{i, t \mid t-1} \mathbf{H}+\mathbf{R}_{i}\right)^{-1} \mathbf{H}^{\prime} \mathbf{P}_{i, t \mid t-1}
$$

Since our goal is to form an inference about the value of $\boldsymbol{\xi}_{i, t}$ based on the full set of time series we compute the smoothed estimate $\widehat{\boldsymbol{\xi}}_{i, t \mid T}$ and the corresponding MSE, $\mathbf{P}_{i, t \mid T}$, by conditioning on next period's observation that is, $\widehat{\boldsymbol{\zeta}}_{i, t \mid T}=\widehat{\boldsymbol{\zeta}}_{i, t \mid t}+\mathbf{J}_{i \tau}\left(\widehat{\boldsymbol{\zeta}}_{i, t+1 \mid T}-\widehat{\boldsymbol{\zeta}}_{i, t+1 \mid t}\right)$ and $\mathbf{P}_{i, t \mid T}=\mathbf{P}_{i, t \mid t}+\mathbf{J}_{i t}\left(\mathbf{P}_{i, t+1 \mid T}-\mathbf{P}_{i, t+1 \mid t}\right) \mathbf{J}_{i t}^{\prime}$ where $\mathbf{J}_{i t}=\mathbf{P}_{i, t \mid t} \mathbf{F}_{i}^{\prime} \mathbf{P}_{i, t+1 \mid t}^{-1} \cdot{ }^{27}$ Wherever there is a missing observation, in each loop of the Markov chain, we replace it with $y_{i, t}^{*}=\boldsymbol{\zeta}_{i, t}^{* 1}+$ $b_{c, i} f_{t}^{c}+b_{s, i} f_{t}^{\mathcal{S}}$ where $\boldsymbol{\xi}_{i, t}^{* 1}$ is the first element of the drawing $\boldsymbol{\zeta}_{i, t}^{*}$ from $N\left(\widehat{\boldsymbol{\xi}}_{i, t \mid T}, \mathbf{P}_{i, t \mid T}\right)$. The values for the missing observations are drawn right after the completion of steps 1 and 2 of the estimation procedure.

\section{Notes}

${ }^{1}$ In the 6th specification of Beaudry and DiNardo (see Table 2 of their paper), in addition to the common (across all wages) current unemployment rate, there are two extra terms affecting real wages: (i) the best market condition (minimum unemployment rate) since the worker was hired and (ii) the market condition (unemployment rate) at the start of the job. When the last two terms are excluded, the coefficient on the current unemployment rate is estimated to be large and significant, whereas when those two terms are incorporated, the coefficient on the current unemployment rate is estimated to be, roughly, zero and statistically insignificant.

${ }^{2}$ Cunha and Heckman (2008) also use a dynamic factor model along with longitudinal microdata to study cognitive and non-cognitive skill formation in early childhood.

${ }^{3}$ The construction of mean real wages is such that it gives more weight to low-skill workers during expansions than during recessions. It is argued that the latter is causing significant countercyclical bias to real wages.

${ }^{4}$ The theoretical backround of implicit contracts lies in the work of Bailey $(1974)$ and Azariadis $(1975,1976)$ and Gordon (1974). Other theories developed to address real wage acyclicality include efficiency wage and insider-outsider models.

${ }^{5}$ While the labor contracting model is consistent with the empirical results, this is not a test of that model as other models might be consistent as well.

${ }^{6}$ Similar results to Cooley and Ogaki are reported by Osano and Inoue (1991) and Beaudry and DiNardo (1991, 1995) and Ham and Reilly (2002) who contrast and test Walrasian and labor contacting models. While the Walrasian models perform poorly in testing, the contracting models cannot be rejected by the data.

${ }^{7}$ The significance of overtime earnings in generating procyclical real wages is also reported by Devereux and Hart (2006), using data from the US, and Anger (2011), using data from Germany. The wage measure used in our analysis includes tips, overtime and bonuses.

${ }^{8}$ Using similar methodology - i.e. regressing current (or first-differenced) real wages to the current (or first-differenced) unemployment rate-, Devereux and Hart (2006), find that job movers exhibit higher real wage procyclicality than job stayers using UK data. Similar results are reported by Carneiro, Guimarães, and Portugal (2012) and Martins, Solon, and Thomas (2012), using Portuguese data and Haefke, Sonntag, and van Rens (2013), using US data. Peng and Siebert (2008) also find that job stayers in Northern Italy have procyclical real wages, especially in the private sector and in smaller firms.

${ }^{9}$ The text of question for the years 1979 to 1993 asks the respondents to report amount earned that includes tips, overtime and bonuses before deductions. The hourly rate of pay in survey year 1994 is calculated a little differently. Respondents are first asked if they are paid hourly; if so, then that reported hourly wage is used in the created hourly rate. Presumably, this hourly wage does not inlcude tips, overtime and bonuses. Otherwise, if the respondents report other than an hourly wage, then they are asked for earnings that include tips, overtime, and bonuses (just as in the years 1979-1993) from which hourly rate of pay is created. Given that there is a difference in methodology for 1994 we exclude this year from our sample.

${ }^{10}$ The reported hourly wage refers to the respondent's current or most recent job at the time of the interview. In the NLS survey the current or most recent job is refered to as job \#1 which, after 1982, is nearly always the CPS job.

${ }^{11}$ We do not use more recent data of the survey for two reasons. First, the number of respondents is decreasing (relative to the initial sample in 1979) which reduces further the number of eligible individuals in our sample. Second, after 1994, individuals are interviewed every two years rather than annually.

${ }^{12}$ This treatment of the data is the same form as the log deviations from steady-state that would come from a DSGE model.

${ }^{13}$ The scales of the factor loadings are separately identified from those of the factors by normalizing the variances of the factors to a constant, as is common in the literature.

${ }^{14}$ Note that only the second type of selection bias, discussed by Keane, Moffitt, and Runkle (1988), could be somewhat relevant to the estimation of the factor model. As described in the text, the latter is addressed by replacing the missing wages by values (implied wages), which are estimated using information both before and after the occurrence of the missing wages as well as cross-sectional information based on the factors and factor loadings.

${ }^{15}$ The sign of the factor is normalized so that it moves in the same direction as an factor extracted from macroeconomic data. This normalization implies that wages fall in a recession.

${ }^{16}$ The correlation coefficients between the wage factor and the macro factor, TFP, the real price of investment, labor productivity and real GDP growth are $0.54,0.17,-0.28,-0.24$ and 0.06 , respectively.

${ }^{17}$ The assumption in the econometric model is that the innovations between the two skill factors is zero. However, this assumption is not imposed in the estimation so the skill factor can be correlated if the data so indicate. We do impose that that aggregate factor is orthogonal to the two skill factors.

${ }^{18}$ Lacombe and Conley (1985) explain the spike in wages shown in 1984. 


\footnotetext{
${ }^{19}$ If productivity were iid then exactly 50 percent of the individuals would be driven by the common factor, but since there is serial correlation in productivity, wages in adjacent periods would be related to each other, which would be picked up by the dynamics in the factor. This would lead to more than 50 percent of the sample having a quantitatively important response to the common factor .

${ }^{20}$ Typically one assumes CRRA utility, Cobb-Douglass production, AR(1) technology shocks and a linear capital accumulation equation.

${ }^{21}$ For the sake of simplicity we omit shocks other than $\theta_{t}$ from our notation; $\theta_{t}$ can also be viewed as a composition of different shocks.

${ }^{22}$ The idea is based on the assumption that capital markets are inadequate to fully buffer the agents' consumption against adverse shocks.

${ }^{23}$ The same condition for the equilibrium wage can be derived when preferences are nonseparable. In that case however, parameter $\lambda_{i}$ is the within period elasticity of substitution between consumption and leisure [see Pourpourides (2011)].

${ }^{24}$ To further motivate our empirical work, consider the simple example where consumption equals labor earnings expressing equilibrium wages and work effort as functions of relevant factors. Then, (9) is written as
}

$$
\frac{-U_{H}^{i}\left(w_{i}\left(f_{t}, \mathbf{f}_{t}^{i}\right) H_{i}\left(f_{t}, \mathbf{f}_{t}^{i}\right), H_{i}\left(f_{t}, \mathbf{f}_{t}^{i}\right)\right)}{U_{C}^{i}\left(w_{i}\left(f_{t}, \mathbf{f}_{t}^{i}\right) H_{i}\left(f_{t}, \mathbf{f}_{t}^{i}\right), H_{i}\left(f_{t}, \mathbf{f}_{t}^{i}\right)\right)}=\psi_{i}\left(\theta_{t}\right)
$$

where $f_{t}$ is a common factor across all individuals and $\mathbf{f}_{t}^{i}$ is a set of factors specific to individual $i$. It can be shown that this model can be reduced to models previously considered in the literature. For instance, if $f_{t}=\nu\left(\theta_{t}, \theta_{t-m}\right)$ for $m \geq 1$, the model reduces to a version of the implicit contracts model of Beaudry and DiNardo (1995). If $f_{t}=\theta_{t}$, the model can be reduced to a standard Walrasian model where $\psi_{i}\left(\theta_{t}\right)=w_{i}\left(\theta_{t}\right)$. In general, the intratemporal condition (9) may correspond to a class of implicit contracts models or a class of Walrasian models. Since each class of models implies a particular relationship between wages and the business cycle, the relationship between $f_{t}$ and $w_{t}$ can be used to draw inferences about the validity of each of these theories.

${ }^{25}$ Alternatively, instead of drawing a value from $L(\cdot)$, we can merely skip the updating equations by assuming that $\widehat{\boldsymbol{\xi}}_{i, \tau \mid \tau}=\widehat{\boldsymbol{\xi}}_{i, \tau \mid \tau-1}$ and $\mathbf{P}_{i, \tau \mid \tau-1}=\mathbf{P}_{i, \tau \mid \tau-1}$. The results do not change significantly under this alternative.

${ }^{26}$ The formulas were directly taken from Hamilton 's (1994) time series textbook. For more details concerning the algorithm refer to Hamilton pp. 377-381.

${ }^{27}$ Refer to Hamilton (1994) pp. 394-397.

\section{References}

Acemoglu, D. 1998. “Why Do New Technologies Complement Skills? Directed Technical Change and Wage Inequality.” Quarterly Journal of Economics 113: 1055-1089.

Anger, S. 2011. “The Cyclicality of Effective Wages Within Employer-Employee Matches in a Rigid Labor Market.” Labour Economics 18 (6): 786-797.

Azariadis, C. 1975. “Implicit Contracts and Unemployment Equilibria." Journal of Political Economy 83: 1183-1202.

Azariadis, C. 1976. "On the Incidence of Unemployment." Review of Economic Studies 43: 115-125.

Bailey, M. N. 1974. "Wages and Unemployment Under Uncertain Demand." Review of Economic Studies 41: 37-50.

Beaudry, P., and J. DiNardo. 1991. "The Effect of Implicit Contracts on the Movement of Wages over the Business Cycle: Evidence from Micro Data." Journal of Political Economy 99 (4): 665-688.

Beaudry, P., and J. DiNardo. 1995. "Is the Behavior of Hours Worked Consistent with Implicit Contracts Theory." Quarterly Journal of Economics 110 (3): 743-768.

Bils, M. J. 1985. “Real Wages over the Business Cycle: Evidence from Panel Data." Journal of Political Economy 96 (6): 666-689.

Boldrin, M., and M. Horvath. 1995. "Labor Contracts and Business Cycles." Journal of Political Economy 103 (5): 972-1004.

Carneiro, A., P. Guimarães, and P. Portugal. 2012. "Real Wages and the Business Cycle: Accounting for Worker, Firm, and JobTitle Heterogeneity." American Economic Journal: Macroeconomics 4 (2): 133-152.

Chib, S., and E. Greenberg. 1994. "Bayes Inference in Regression Models with ARMA(p,q) Errors." Journal of Econometrics 64: 183-206.

Cooley, T. H., and M. Ogaki. 1996. "A Time Series Analysis of Real Wages, Consumption and Asset Returns." Journal of Applied Econometrics 11: 119-134.

Cunha, F., and J. J. Heckman. 2008. “Formulating, Identifying and Estimating the Technology of Cognitive and Noncognitive Skill Formation." Journal of Human Resources 43 (4): 738-782.

Devereux, P. J. 2001. “The Cyclicality of Real Wages Within Employer-Employee Matches." Industrial and Labor Relations Review 54: 835-850.

Devereux, P. J., and R. A. Hart. 2006. "Real Wage Cyclicality of Job Stayers, Within-Company Job Movers, and Between-Company Job Movers." Industrial and Labor Relations Review 60: 105-119.

Cordon, D. F. 1974. “A Neo-classical Theory of Keynesian Unemployment." Economic Inquiry 12: 431-459.

Haefke, C., M. Sonntag, and T. van Rens. 2013. "Wage Rigidity and Job Creation." Journal of Monetary Economics 60: 887-899.

Ham, J. C., and K. T. Reilly. 2002. "Testing Intertemporal Substitution, Implicit Contracts, and Hours Restriction Models of the Labor Market Using Micro Data." American Economic Review 92 (4): 905-927.

Hamilton, J. D. 1994. Time Series Analysis. Princeton, N]: Princeton University Press.

Katz, L. F., and K. M. Murphy. 1992. “Changes in Relative Wages, 1963-1987: Supply and Demand Factors.” Quarterly Journal of Economics 107 (1): 35-78.

Keane, M., and E. Prasad. 1993. "Skill Levels and the Cyclical Variability of Employment, Hours, and Wages." IMFStaffPapers 40 (4): $711-743$.

Keane, M., R. Moffitt, and D. Runkle. 1988. "Real Wages over the Business Cycle: Estimating the Impact of Heterogeneity with Micro Data." Journal of Political Economy 96 (6): 1232-1266.

King, R., C. Plosser, and S. Rebelo. 1988. "Production, Growth and Business Cycles I: The Basic Neoclassical Model." Journal of Monetary Economics 21: 195-232.

Kose, A., C. Otrok, and H. C. Whiteman. 2003. "International Business Cycles: World, Region, and country-specific factors." American Economic Review 93 (4): 1216-1239. 
Krusell, P., L. E. Oharian, J. V. Rios-Rull, and C. L. Violante. 2000. “Capital-Skill Complementarity and Inequality.” Econometrica 68: 5. Lacombe II, J. J., and J. R. Conley. 1985. “Major Agreements in 1984 Provide Record Low Wage Increases.” Monthly Labor Review 108 (4): $39-45$. Martins, P. S., G. Solon, and J. P. Thomas. 2012. "Measuring What Employers Do About Entry Wages over the Business Cycle: A New Approach." American Economic Journal: Macroeconomics 4 (4): 36-55.

Osano, H., and T. Inoue. 1991. "Testing Between Competing Models of Real Business Cycles." International Economic Review 32 (3): 669-688.

Otrok, C., and H. C. Whiteman. 1998. "Bayesian Leading Indicators: Measuring and Predicting Economic Conditions in lowa." International Economic Review 39 (4): 997-1014.

Peng, F., and W. S. Siebert. 2008. “Real Wage Cyclicality in Italy.” Labour 22 (4): 569-591.

Pourpourides, P. M. 2011. "Implicit Contracts and the Cyclicality of the Skill-Premium." Journal of Economic Dynamics and Control 35: 963-979.

Sargent, T. J. 1989. "Two Models of Measurements and the Investment Accelerator." Journal of Political Economy 97 (2): $251-287$.

Sargent, T. J., and C. Sims. 1977. "Business Cycle Modeling Without Much A Priori Economic Theory." In New Methods in Business Cycle Research. Federal Reserve Bank of Minneapolis.

Shin, D. 1994. “Cyclicality of Real Wages Among Young Men." Economics Letters 46: 137-142.

Shin, D., and C. Solon. 2006. "New Evidence on Real Wage Cyclicality Within Employer-Employee Matches." National Bureau of Economic Research, working paper 12262.

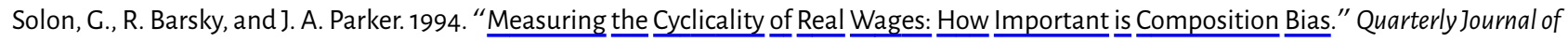
Economics 109 (1): 1-25.

Verdugo, G. 2016. “Real Wage Cyclicality in the Eurozone Before and During the Great Recession: Evidence from Micro Data." European Economic Review 82: 46-69.

Ziliak, J. P., B. A. Wilson, and J. A. Stone. 1999. "Spatial Dynamics and Heterogeneity in the Cyclicality of Real Wages." Review of Economics and Statistics 81 (2): 227-236. 